International Journal of Linguistics, Literature and Culture
Available online at https://sloap.org/journals/index.php/ijllc/
Vol. 7, No. 1, January 2021, pages: 12-22
ISSN: 2455-8028
https://doi.org/10.21744/ijllc.v7n1.1102

\title{
The Effectiveness of the Problem Solving Method on Learning Outcomes of the English Course for Room Division Operation during the COVID-19 Pandemic
}

\author{
I Nyoman Kanca ${ }^{\text {a }}$ \\ Gede Ginaya $^{\text {b }}$ \\ Ni Nyoman Sri Astuti ${ }^{c}$
}

Article history:

Submitted: 27 August 2020

Revised: 09 October 2020

Accepted: 18 November 2020

\section{Keywords:}

COVID-19;

English learning outcomes;

pandemic;

problem-solving;

room division course;

\begin{abstract}
This study aims to determine how much effective problem-solving methods are in the third semester of English learning outcomes in the Hospitality Study Program, Tourism Department, Bali State Polytechnic during the Covid-19 pandemic. The background in this study is the lack of student enjoyment in English, inappropriate learning strategies, and the lack of developing student creativity in the learning process. This type of research is quantitative research. Data collection techniques using observation, tests, and documentation. Participants consisted of 60 (29 male and 31 female) thirdsemester students of the Diploma 3 Program, Hospitality, Bali State Polytechnic, 2020/2021 academic year. The data were collected through a classroom action-based research procedure starting from planning, acting, observing, and reflecting. Through the quasi-experimental design, the collected data were analyzed using paired t-tests and mixed design ANCOVA to identify any significant improvement after the administration of the action. Furthermore, the qualitative data were analyzed based on the results of observations during the giving of the action and the results of the questionnaire. The results of the analysis showed that the participants who received the treatment, their English communicative competence increased significantly, 63.05 in the control group and 84.43 in the experimental group $[\mathrm{t}=-23.485, \mathrm{p}=.000]$ at the level of $\mathrm{p}<.05$. This increase was also followed by an increase in student motivation and interest in learning. It can be concluded that the effective problem-solving method is used in the English for Room Division course.
\end{abstract}

International journal of linguistics, literature and culture (C) 2021. This is an open access article under the CC BY-NC-ND license (https://creativecommons.org/licenses/by-nc-nd/4.0/).

\section{Corresponding author:}

I Nyoman Kanca,

Politeknik Negeri Bali, Denpasar, Indonesia.

Email address: nyomankanca@pnb.ac.id

${ }^{\text {a }}$ Politeknik Negeri Bali, Denpasar, Indonesia

${ }^{\mathrm{b}}$ Politeknik Negeri Bali, Denpasar, Indonesia

${ }^{\mathrm{c}}$ Politeknik Negeri Bali, Denpasar, Indonesia 


\section{Introduction}

Education in vocational colleges, such as Polytechnics, is an effort carried out to develop student potential as learners in these vocational education institutions through the process of teaching and learning activities. By looking at the situation that there are two problems faced, namely, the quality of education and the learning system on campus. The notion of education itself is a process that has been carried out that has become one in the life of the world because with a good education, humans will gain and master the knowledge they get. With education, someone who previously did not know anything will get useful knowledge.

English has an important role in the world of education. With the existence of English as a foreign language, students will learn to reason critically, creatively, and actively. Learning English can be said to be successful if the learning is following the objectives of teaching English and students are seen in mastering English courses. In learning English, the task of a lecturer is very important (Liu \& Chu, 2010; Miyazoe \& Anderson, 2010). The task of a lecturer is to be able to generate a more meaningful learning atmosphere by relating it to everyday life. Thus, learning English has a very important role in utilizing real proof.

Learning English with problem-based learning strategies can be the right solution to apply. This learning strategy was developed from discovery learning as the opposite of expository learning. The discovery of the learning method itself was first introduced by Jerome Bruner in 1960 (Thorsett, 2002). According to Richards \& Rodgers (2014), problem-solving learning is where "students develop processes related to discovery and investigation by observing, concluding, formulating hypotheses, predicting, and communicating. Holesinska (2006), states that problem-solving learning strategies are the most practical and encouraging examples of active learning strategies in which students must formulate rules and find their text concepts.

Likewise, Thorsett (2002), defines problem-solving as a learning situation where the main content of what is to be learned is not given but must be discovered independently by students, making students active participants in their learning. Balin et al., (2011), provides a strong definition of problem-solving as a strategy that encourages students to arrive at conclusions based on their activities and observations. This is also supported by Nutting (2013), that this strategy can also bring out student creativity because there are two exploratory activities carried out by them, namely observation and experimentation. According to Saumell (2012), problem-solving is a modified inductive approach in which there is first language exposure, followed by the use of inference, and finally an explicit focus on rules and practices.

It is further stated that problem-solving learning has cognitive, linguistic, and social benefits, namely encouraging analytical learning, exploiting participants' cognitive skills, increasing critical thinking skills, involving students in problem-solving tasks, helping students become aware and articulate their mental processes. Learners participate actively in the learning process, understand, and remember better what they have done for themselves. The benefit of linguistics is that it resembles natural language learning, if done in groups will provide additional language practice. Social benefits are increasing student participation and encouraging collaboration, empowering students to increase autonomy and independence. This is motivating for learners who enjoy a hands-on approach (Bakkenes et al., 2010).

Since the pandemic, the government has taken various ways to prevent the spread of the coronavirus. This method is an effort to prevent the spread of covid-19. The government continues to strive for learning to continue as usual. According to Adib Rifqi Setiawan in the journal of education science that distance learning is learning that is carried out without face to face directly, that is, students and teachers are not physically present at the same time. Learning is done not face to face directly. On the other hand, to keep education going well following government instructions to study at home. The learning process at home also has provisions, namely, learning can be done at home through distance learning which is carried out to provide a learning experience that is a more meaningful learning process (Sweller, 1988; Nezu, 2004).

Besides, learning activities and assignments take into account existing facilities at home. According to Firman and Sari Rahayu Rahman's research in the journal of educational science, the use of the internet and technology can facilitate the delivery of knowledge. The school and students and their parents make it a habit to implement onlinebased learning. According to the research results of Zainal Abidin, Rumansyah and Kurniawan Arizona regarding scientific journals of the educational profession, the average learning outcomes taught through online learning methods have increased better than the average learning outcomes taught by conventional methods. Lecturers are expected to be able to design learning so that learning can take place effectively by using the available applications. The researcher intends to research the effectiveness of problem-solving methods on the learning outcomes of the third semester English for Room Division, Hospitality Studies Program, Department of Tourism, Bali State

Kanca, I. N., Ginaya, G., \& Sri Astuti, N. N. (2020). The effectiveness of the problem solving method on learning outcomes of the English course for room division operation during the COVID-19 pandemic. International Journal of Linguistics, Literature and Culture, 7(1), 12-22. https://doi.org/10.21744/ijllc.v7n1.1102 
Polytechnic during the COVID-19 pandemic. Online learning is applied, of course, by combining problem-solving methods with various applications used. Based on these problems, it is necessary to have effective learning that must be applied. Teaching and learning activities can be said to be effective if the results obtained are much better than before. The purpose of this study was to determine how the effective problem-solving method was in the learning outcomes of the third semester English for Room Division, Hospitality Study Program, Department of Tourism, Bali State Polytechnic during the COVID-19 pandemic.

\section{Materials and Methods}

\section{Location and time of research}

This research was conducted in the Bali State Polytechnic Tourism Department, namely in class 3A and 3B of the Hospitality Study Program. Regarding the time of research, research activities will be carried out for 3 months (September - November 2020).

\section{Research population and sample}

The subjects of this study were third-semester students, namely classes 3A and 3B of the Hospitality Study Program, Department of Tourism, Bali State Polytechnic, 2020/2021 academic year. They learn English with the English for Room Division Operation course four hours a week. The appointment of classes 3A and 3B as research subjects was based on the problems faced by the English teaching team in this class in the previous semester where class interactions and the achievement of learning oral communication (oral task/practice) students in this class were still low with an average score. English 60.5. This score is still far from the minimum passing grade, which is 76 (B) for the ESP English course. Sampling as the subject of this study is following the theory put forward by Cresswell (2014), that the single sampling technique procedure is sampling where the researcher has access to identify names in the population and can select them directly.

\section{Research instrument}

Several instruments will be used to conduct this research. The instruments needed depend on the type of activity carried out. At the time of giving the learning action, three kinds of instruments are needed, namely (1) teaching diary, (2) observation sheets, (3) questionnaire. The diary is used to observe the results of giving actions that include students' daily class interactions and their communicative competence abilities. In other words, this diary is used to record learning situations such as student responses to providing authentic material, problems faced by students. So this diary is used to record all situations and conditions during the teaching and learning process. Observation sheets are used to record student class interactions in groups, pairs, and interactions between students and lecturers.

When measuring students' communicative competence, a test instrument is needed, namely an oral test which consists of five aspects: (1) accuracy (grammar and vocabulary), (2) fluency, (3) intonation, (4) expression, and (5) ) theme. To obtain data related to student feelings, motivation, and interest in each learning cycle, a questionnaire is needed. A questionnaire is also required when creating a benchmark test to validate the test. An assessment rubric instrument is also needed to convert the values achieved by participants. Before being used, several instruments need to be validated. The instrument that will be validated is a questionnaire to determine the characteristics of students that will be used as a preliminary test to determine the baseline of students' communicative competence abilities, T1, $\mathrm{T} 2$, and $\mathrm{T} 3$ to measure the effectiveness of using authentic material in giving the first action (cycle 1), giving the second action (cycle 2), and giving the third action (cycle 3). This material testing activity was carried out in class through Focus Group Discussions (FGD) involving participants from different classes.

\section{Method of data collection}

This study uses a classroom action research method. Classroom action research can be defined as a cyclic process of planning, action, observation, and reflection (Kemmis \& Taggart, 1988). In this study, the study was conducted in three cycles and each cycle was completed in two session sessions. Before the research was conducted, a prespeaking test was given to students. Therefore, the data collection method used in this study was a survey method 
using one interview guide. Interviews were conducted by researchers and surveyors at graduate user industries in Bali to obtain authentic material following industry standards. Interviews were conducted by following semistructured interview guidelines. The authentic material is used to compile teaching materials so that learning in the classroom becomes contextual following the existing realities in the industrial world today.

\section{The technique of data analysis}

The data were analyzed in two ways, namely quantitative and qualitative. Quantitative data were analyzed based on oral presentations during the learning period. The students' communicative competence scores at initial observation and pretest (test 1) were analyzed using the SPSS-17.0 program and t-test to ensure equality between the experimental group and the control group. Meanwhile, students' scores in the posttest (test 2) were re-analyzed using SPSS. Then, the parallel sample t-tests in the two groups were calculated to determine the difference between the pretest and posttest in each group. To determine differences in English communicative competence between the experimental and control groups in the post-test, an analysis of covariance (ANCOVA) was carried out (Kemmis et al., 2013). Meanwhile, the qualitative data were analyzed based on the results of observations made after the treatment and the results of filling out the questionnaire.

In this case, the conditions and situation of the class during the learning process, the interaction, motivation, attitudes, and interests of students in doing exercises and communicative activities are analyzed to determine the effectiveness of the learning model applied. Also, it is to find out the problems that students may face during the teaching and learning process, which causes their communicative English competence to not improve. Furthermore, the classified data is analyzed using a qualitative descriptive method based on the inductive methodological paradigm, namely the exposure of the problem from specific to general to conclude (Ginaya, 2018).

\section{Results and Discussions}

\subsection{Result of data analysis and discussion}

The data obtained based on the method applied in the previous chapter were analyzed in two ways, namely quantitative and qualitative. Quantitative data were analyzed based on oral presentation performance during the teaching and learning process. Student scores in the initial observation (test 1) were analyzed using the SPSS-17.0 program and the t-test was calculated to ensure the experimental and control groups were at the same ability level. Meanwhile, the students' scores in the posttest (test 2) were analyzed again using SPSS. Then, a sample t-test in the parallel groups of the two groups was counted as an attempt to investigate the differences between the pretest and posttest in each group.

The difference in post-test scores between the experimental and control groups was carried out through covariance analysis (ANCOVA). Meanwhile, qualitative data were analyzed based on the results of observations made after the treatment was applied, and the results of distributing questionnaires. In this case, the conditions and situation of the class during the learning process, interaction, motivation, attitudes, and student interest in exercising and communicative activities are analyzed to determine the effectiveness of the learning model applied. Also, to find out the problems faced by students during the teaching and learning process, which causes students to be unable to improve their communicative competence. Therefore, there are several things discussed in this section.

\subsection{The result of pretest}

There are 15 topics discussed in the course of Tourism English in semester 3 and each topic consists of two meeting sessions a week. 3 topics were selected for integrated learning. Learning is carried out for 3 weeks with 2 meeting sessions each week. Before students receive treatment, the experimental and control groups are taught using conventional methods for one week or two session sessions. After the teaching and learning process was carried out, a pretest (test 1) was given to both groups in the following week to ensure that the subject of this study was students' communicative competence at the same level. The pretest results show that the mean scores are very similar as seen in table 1. These results were calculated via the Independent Samples Test (t-test), which is calculated at the $\mathrm{p}<.05$ level in the scores for the two groups $[\mathrm{t}=-.117, \mathrm{p}=.908]$.

Kanca, I. N., Ginaya, G., \& Sri Astuti, N. N. (2020). The effectiveness of the problem solving method on learning outcomes of the English course for room division operation during the COVID-19 pandemic. International Journal of Linguistics, Literature and Culture, 7(1), 12-22. https://doi.org/10.21744/ijllc.v7n1.1102 
Table 1

Result of t-test calculation for Group Equality Level

\begin{tabular}{lllllll}
\hline Method & Group & Total & Average & St. deviation & t table & Sig. (2 tailed $)$ \\
\hline Conventional & Control & 23 & 55.4393 & 6.34 & .117 & \multirow{2}{*}{908} \\
Conventional & Experiment & 28 & 55.2609 & 5.26 & .17 \\
\hline
\end{tabular}

Based on the table above, the mean score of the student pretest results was 55.44 in the control group and 55.26 in the experimental group. This mean value is categorized as low, also, students become unfocused, less enthusiastic, and often do other things during the teaching and learning process.

\subsection{The result of treatment}

Starting from the results of observations at the beginning of the study and giving a pretest, the research continues with the provision of treatment. In the planning step, researchers focused on efforts to improve student communicative competence through integrated learning in the experimental group. Therefore, the planning of learning scenarios and instruments was prepared before giving any action. After taking action in 3 learning cycles, this section discusses the results of each learning cycle. There are 15 topics discussed in the semester lecture plan and each topic consists of two session sessions per week. Each meeting session was given action in the form of practice and communicative activities on each topic discussed. Starting from the results of observations in the first week of learning, the research begins with the first cycle. At the planning stage, the research began by preparing scenarios and learning instruments with the topic of dealing with incoming calls on etiquette for receiving incoming calls at hotels. The next step is giving action using brainstorming techniques, pair work, and group discussions. All student learning activities are recorded on the observation sheet and daily notes. At the end of the meeting, a test to measure students' communicative competence was given.

The mean value of the test results achieved by students in cycle 1 was 63.05. These results indicate an increase in learning outcomes when compared with the pretest results, namely 55.26. Even though the student's achievement in this cycle was higher than that of the pretest, based on the results of the observations throughout this cycle it was found that students still felt not too confident, and slow students also found themselves still having difficulty adjusting to other friends in group discussions. Knowing the weaknesses in cycle 1, reflection is carried out with the conclusion that students need facilitation during the exploration process which can reduce the factors that cause them to be less than optimal in learning, such as learning less conducive security. Therefore, business games and roleplaying are considered in giving action in cycle 2 .

Learning cycle 2 is carried out in the third week and the topic of discussion is customer information, which includes providing information to guests, answering guest questions about hotel facilities and services. The steps carried out in cycle 2 are the same as in the previous cycle, namely starting with the preparation of a learning scenario in which giving actions is facilitated by business games and role-playing in exercises and communicative activities. At the observation stage of this cycle, students began to feel comfortable, became more active in participating in group discussions and they were interested in doing exercises and communicative activities facilitated by business games and role-play. However, it was found that some students often borrowed the work of their friends in their respective groups before making presentations. This problem is identified as a short-term learning utility. After reflecting on this problem, it is anticipated by facilitating exercises and communicative actions using techniques in the form of web-based project tasks (WebQuest) and problem-solving in cycle 3 learning. Learning cycle 3 is carried out in the fourth week starting with classroom instructions about the WebQuest application through e-learning. After the students are divided into small groups, namely 4-5 groups, then they register on the Edmodo e-learning application portal. Furthermore, students can access WebQuest project assignments on the topic of dealing with check-in problems. In this case, the whole learning process is carried out interactively between lecturers and students online. In the second session of the fourth week, group discussions about the WebQuest project task and also problem-solving techniques were carried out. As a reflection of this cycle 3, students become very motivated in learning English. However, this study only consisted of three learning cycles so the study was stopped.

After giving the action to the three learning cycles was completed, at week 5 posttest (test 2) to measure the communicative competence of students was given to both groups, both experimental and control groups. The communicative competency test is in the form of a speaking test which includes a series of situations in the context 
of the room division operation, such as taking reservations, welcoming guests, and explaining how things work in the hotel room. The mean post-test scores achieved by students in the control group were 63.05 and 84.43 in the experimental group. To answer the question of the first problem formulation (Is there a significant increase in the posttest communicative competency scores of the control and experimental groups?), Descriptive analysis and the pair t-test sample were used to determine the statistically significant differences in the results of post-testing between the two groups of students. Table 2 below shows the results of the t-test sample pairs that count the communicative competence scores of students in the control group.

Table 2

Results of the Pair of Sample Test Count $t$ in the Control Group (Difference between Pre- and Post-Test)

\begin{tabular}{llllllll}
\hline Group & Variable & Test & Total & Average & St. Deviation & t hitung & Sig. (2- tailed) \\
\hline Control & Competence & Pre & 23 & 55.4393 & 5.71849 & \multirow{2}{*}{5.417} & \multirow{2}{*}{$.000^{* *}$} \\
& Communicative & Pos & 23 & 63.0536 & 6.69209 & & \\
\hline
\end{tabular}

** level of significance. 05

Table 2 shows that the communicative competence of students in the control group increased significantly [ $\mathrm{t}=$ $6,932, \mathrm{p}=.000]$. There was a significant difference between student performance at pre-and post-test instructions at the level of $\mathrm{p}<.01$. This result could be due to the existence of an explicit explanation of the functional grammar rules which was more intensive than the pre-test learning so that students were better prepared to do exercises and practice communicative activities. Figure 1 below shows the mean scores obtained by the control group in the preand post-tests.

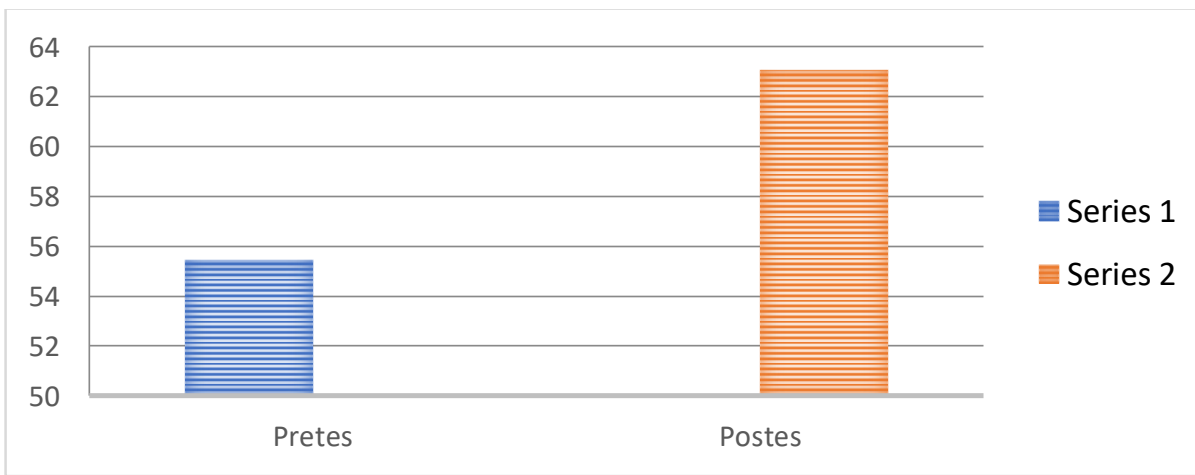

Figure 1. Average Score of Group Communicative Competence controls on pre-and post-tests

The following table 3 shows the results of the t-test sample pairs that count the communicative competence values of students in the experimental group.

Table 3

Results of the sample pair test count $t$ in the experimental group (the difference between pre-and post-test)

\begin{tabular}{llllllll}
\hline Group & Variable & Test & Total & Average & St. Deviation & t hitung & Sig. (2- tailed) \\
\hline \multirow{2}{*}{ Experiment } & Competence & Pre & 28 & 55.2609 & 5.06294 & \multirow{2}{*}{23.485} & \multirow{2}{*}{$.000^{* *}$} \\
& Communicative & Post & 28 & 84.4348 & 4.64979 & & \\
\hline
\end{tabular}

** level of significance.05

Table 3 shows that the communicative competence of students in the experimental group increased significantly [ $\mathrm{t}=$ $-25.185, \mathrm{p}=.000]$. This result is due to the existence of intense practice and practice of English in practice and communicative activities so that the average score margin between pretest and posttest is higher in the experimental group than in the control group. The overall view of the above results from the experimental group can be seen below in Figure 2.

Kanca, I. N., Ginaya, G., \& Sri Astuti, N. N. (2020). The effectiveness of the problem solving method on learning outcomes of the English course for room division operation during the COVID-19 pandemic. International Journal of Linguistics, Literature and Culture, 7(1), 12-22. https://doi.org/10.21744/ijllc.v7n1.1102 


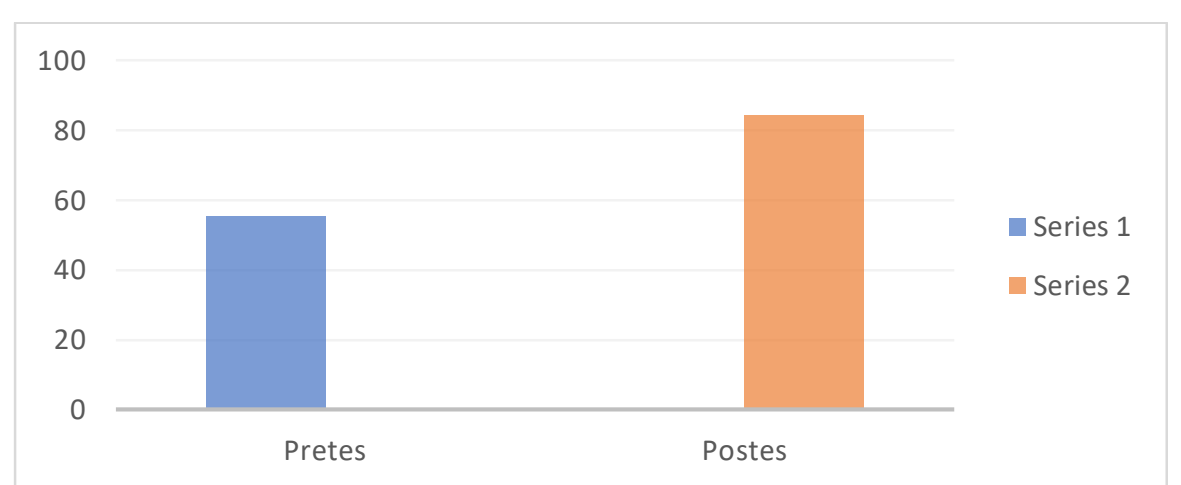

Figure 2. The average score of group communicative competence experiments on pre-and post-tests

The results of both groups indicated that there was a significant increase in the speaking performance of the students after receiving the treatment. To determine the extent of the treatment effect, especially to answer the second problem formulation (Is there a significant difference between the control and experimental groups in the posttest?), Covariance analysis (ANCOVA) was used concerning the obtained pretest score.

Table 4

ANCOVA test for the control group and experiment group posttest results on pretest effect

\begin{tabular}{llllllr}
\hline Method & Group & No & Average & St. deviation & F & Sig. \\
\hline Conventional & Control & 23 & 63.0536 & 6.69209 & 90.888 & $000 * *$ \\
Induktif & Experiment & 28 & 84.4248 & 4.64979 & & \\
\hline
\end{tabular}

level of significance $.05^{* *}$

Table 4 shows that there was a significant difference between the experimental and control groups in the post-test controlling for the pre-test scores $[\mathrm{F}=24,286, \mathrm{p}=0.000]$ at the $\mathrm{p}<.01$ level. The very significant difference in student communicative competence strengthens the results of the analysis that the inductive learning method using authentic material can improve students' communicative competence. Figure 3 below shows the difference in the mean post-test scores of the two groups.

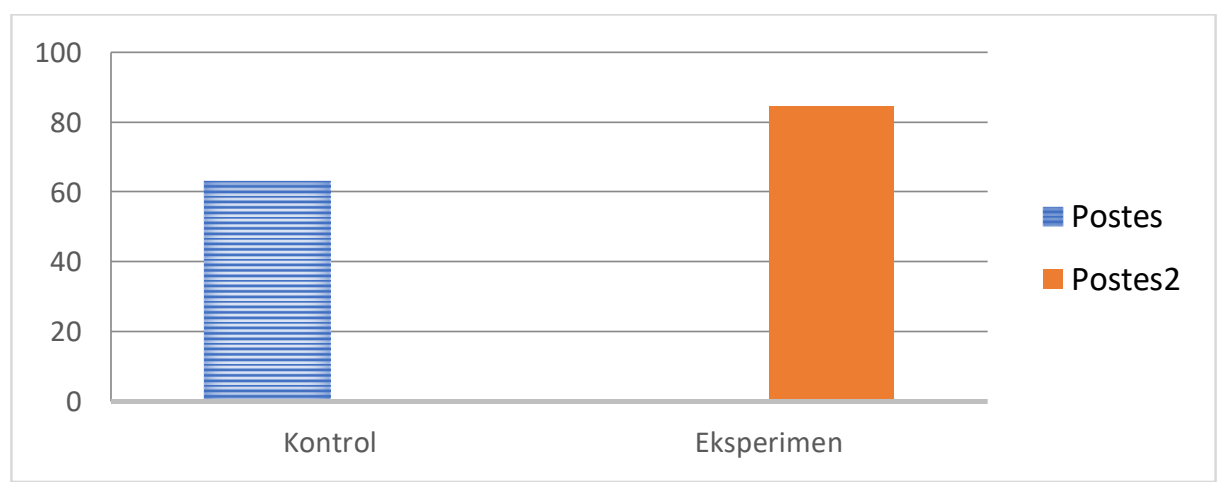

Figure 3. The average score of group communicative competence control and experiment on the posttest

The figure shows that the experimental group's mean score was higher than the control group in the post-test. This means that there is a significant difference between the application of conventional teaching methods that are deductive, namely presentations, exercises, communicative activities, and problem-solving methods embedded in the modified conventional learning model, namely communicative activities, exercises, presentations. Student responses to the application of learning with the problem-solving method in the English for Room Division Operations course showed positive results. Evidence of this statement can be seen from the results of filling out the questionnaire in each learning cycle. In cycle 1 there were $22 \%$ of students said that they were very happy and there were $75 \%$ of 
them said that they were happy, and 3\% said that they were happy or unhappy when they were asked about their feelings and interest in learning English through integrated learning. as shown in figure 3 below

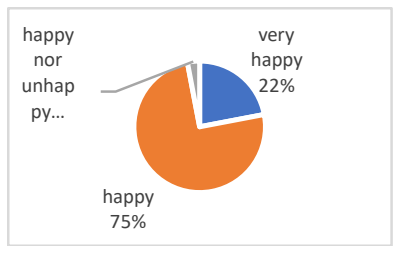

Figure 3. Students' perceptions of the implementation of problem-solving method

Students' positive perceptions of the application of problem-solving methods are shown through the active participation of students in-class interactions. However, there are several problems faced by students during the teaching and learning process, such as some students feel less confident in communicating using English because they are afraid of making mistakes in grammar and pronunciation, limited vocabulary and use of expressions in producing speech, it is difficult to understand of what other students said during the presentation. However, most students said that integrated learning could minimize the problems faced by these students, because of the facilitation of exercises and communicative activities using group discussion techniques, pair work, business games, roleplaying, web-based project assignments, and problem-solving. Problem-solving is done interestingly, so that it can eliminate negative factors in the learning process, such as boredom, doubt, and fear in learning.

\section{Discussion}

The results showed that the problem-solving method in learning English for Room Division Operation had a very significant effect on students' communicative English competence. This was proven after classroom action research was carried out in three learning cycles for the experimental group. After giving action in each learning cycle, namely cycle 1 facilitated with brainstorming, pairwork, and group discussion, cycle 2 with business games and roleplaying, and cycle 3 with WebQuest and problem-solving. A significant increase in students' English competence was also seen in the comparison of the mean scores between pretest and posttest.

This increase was also supported by increased motivation and interest in learning as shown by the results of filling out the questionnaire. The questionnaire was formulated based on 3 main indicators, namely (1) effectiveness in the learning process both in offline and online activities; (2) learning concept based on WebQuest project in learning cycle 3; (3) student achievement in pre and posttest. In general, students have high learning interest and motivation to do exercises and communicative activities in each learning cycle. In this case, scaffolded and blended learning techniques are two keywords for the success of student learning achievement. With the scaffolding technique (Ginaya et al., 2018), students get direction on the rules and principles of the grammar system, vocabulary, and word selection to create a sentence context. This directive is designed in such a way as the scaffolding technique as temporary support for concrete in building construction and when the concrete is considered strong enough then the scaffold will slowly be removed, as well as learning these rules and principles while temporary assistance is provided to maximize student prerequisite knowledge to obtain understanding the rules of the language and then slowly and surely students are allowed to do both exercises and communicative activities on their own. Meanwhile, blended learning (Ginaya et al., 2018), was given in cycle 3 through the WebQuest project assignment by utilizing communication and information technology that strengthens face-to-face learning in class. Students are eager to work online to obtain extensive information, some current problems, and knowledge accessed via the internet and web in the context of project assignments based on the topics discussed in cycle 3.

Students' perceptions of learning that can be categorized as blended learning are very positive where students are very satisfied with web-based learning techniques and this problem-solving method. This supports the findings of Ginaya et al. (2018), which examined the effect of blended learning on the speaking ability of 3rd-semester students of the Bali State Polytechnic Travel Business Study Program. This study reveals that the WebQuest project assignment as a learning method through the use of technology to strengthen conventional learning can significantly improve students' speaking skills. Web-based project assignments or WebQuest strongly support students' productive speaking skills because these projects integrate several advantages of language learning, such as analysis, synthesis, evaluation, assessment, problem solving and student creativity.

Kanca, I. N., Ginaya, G., \& Sri Astuti, N. N. (2020). The effectiveness of the problem solving method on learning outcomes of the English course for room division operation during the COVID-19 pandemic. International Journal of Linguistics, Literature and Culture, 7(1), 12-22. https://doi.org/10.21744/ijllc.v7n1.1102 
In addition, class interactions are very lively with the existence of learning techniques from brainstorming to problem-solving, making students interact maximally, such as in problem-solving techniques, students trying to find a better solution as an effort to solve a problem. Communicative exercises and activities aim to stimulate students' language creativity. In this case, student participation in the teaching and learning process increases well. It also means that students experience enjoyable learning and they are encouraged to work hard by maximizing their potential to communicate in English. Therefore, the communicative competence of students increased significantly as shown in the post-test results. Also, students get some important input about the use of English from various sources both online and offline in making practice assignments and communicative activities that help students deal with real situations that they are likely to face in the future.

On the other hand, conventional learning in the control group is very inadequate where the instructions received by students are very monotonous, so they cannot perform optimally during the teaching and learning process. As a result, motivation and interest in learning are low, resulting in low learning participation. On the other hand, through scaffolding and web exploration techniques, students in the experimental group were guided to explore pre-selected web material that was rich in quantity and relevant and described quality for learning content. Students browse online sites as a learning repertoire (Laborda, 2009). In other words, web material in the WebQuest task project provides knowledge as language input which Doughty \& Long (2003), describe as linguistic complexity, quality, quantity, variety, authenticity, and relevance of the learning material they acquire when they surf the internet. Therefore, exposure to rich, relevant, and complex language input is a scientific finding as to why students in the experimental group were far superior to students in the control group in terms of their level of communicative competence.

\section{Conclusion}

On the other hand, conventional learning in the control group is very inadequate where the instructions received by students are very monotonous, so they cannot perform optimally during the teaching and learning process. As a result, motivation and interest in learning are low, resulting in low learning participation. On the other hand, through scaffolding and web exploration techniques, students in the experimental group were guided to explore pre-selected web material that was rich in quantity and relevant and described quality for learning content. Students browse online sites as a learning repertoire (Laborda, 2009). In other words, web material in the WebQuest task project provides knowledge as language input which Doughty \& Long (2002), describe as linguistic complexity, quality, quantity, variety, authenticity, and relevance of the learning material they acquire when they surf the internet. Therefore, exposure to rich, relevant, and complex language input is a scientific finding as to why students in the experimental group were far superior to students in the control group in terms of their level of communicative competence.

\section{Suggestion}

Considering the above conclusions, e-learning using problem-solving methods in modified-conventional learning is an innovative learning model as an alternative to learning English. In this case, lecturers should actively facilitate scaffolded and blended learning techniques to make students motivated, engaged, active, and creative in doing exercises and communicative activities so that learning English becomes fun. Also, the learning process through communicative exercises and activities can arouse students' critical thinking skills, such as comparing, classifying, inducing, concluding, analyzing mistakes, building support, abstraction, analyzing perspectives. Therefore, the creativity of lecturers in designing fun and dynamic exercises and communicative activities can stimulate student interest in learning and motivation. 
Conflict of interest statement

The authors declared that they have no competing interests.

Statement of authorship

The authors have a responsibility for the conception and design of the study. The authors have approved the final article.

\section{Acknowledgments}

The authors are very grateful to some parties who have given contributions and encouragements in completing this article. Particular thanks are owed to Kementerian Riset, Teknologi dan Pendidikan Tinggi of Republic Indonesia who funded the authors' research in the scheme of DRPM-PTUPT.

Kanca, I. N., Ginaya, G., \& Sri Astuti, N. N. (2020). The effectiveness of the problem solving method on learning outcomes of the English course for room division operation during the COVID-19 pandemic. International Journal of Linguistics, Literature and Culture, 7(1), 12-22. https://doi.org/10.21744/ijllc.v7n1.1102 


\section{References}

Bakkenes, I., Vermunt, J. D., \& Wubbels, T. (2010). Teacher learning in the context of educational innovation: Learning activities and learning outcomes of experienced teachers. Learning and instruction, 20(6), 533-548. https://doi.org/10.1016/j.learninstruc.2009.09.001

Ballin, L., Balandin, S., Stancliffe, R. J., \& Togher, L. (2011). Speech-language pathologists' views on mentoring by people who use speech generating devices. International journal of speech-language pathology, 13(5), 446-457.

Cresswell, J. (2014). Research design. Thousand Oaks: Sage publications.

Doughty, C. J., \& Long, M. H. (2003). Optimal psycholinguistic environments for distance foreign language learning. Language learning \& technology, 7(3), 50-80.

Ginaya, G. (2018). The Balinese calendar system: From its epistemological perspective to axiological practices. International journal of linguistics, literature and culture, 4(3), 24-37.

Ginaya, G., Aryana, I. N. R., \& Somawati, N. P. (2018). Improving Students' Speaking Ability through Scaffolding Technique. Soshum: Jurnal Sosial dan Humaniora, 8(1), 72-85.

Ginaya, G., Rejeki, I. N. M., \& Astuti, N. N. S. (2018). The effects of blended learning to students' speaking ability. International journal of linguistics, literature and culture, 4(3), 1-14.

Holešinská, A. (2006). Teaching English as a foreign language to students with learning difficulties (Doctoral dissertation, Masarykova univerzita, Pedagogická fakulta).

Kemmis, S., \& Taggart, R. (1988). The Action Planner (Geelong, Deakin University Press).

Kemmis, S., McTaggart, R., \& Nixon, R. (2013). The action research planner: Doing critical participatory action research. Springer Science \& Business Media.

Laborda, JG (2009). Using webquests for oral communication in English as a foreign language for Tourism Studies. Journal of Educational Technology \& Society, 12 (1), 258-270.

Liu, T. Y., \& Chu, Y. L. (2010). Using ubiquitous games in an English listening and speaking course: Impact on learning outcomes and motivation. Computers \& Education, 55(2), 630-643. https://doi.org/10.1016/j.compedu.2010.02.023

McDonough, J., \& Shaw, C. (2012). Materials and Methods in ELT. John Wiley \& Sons.

Miyazoe, T., \& Anderson, T. (2010). Learning outcomes and students' perceptions of online writing: Simultaneous implementation of a forum, blog, and wiki in an EFL blended learning setting. System, 38(2), 185-199. https://doi.org/10.1016/j.system.2010.03.006

Nezu, A. M. (2004). Problem solving and behavior therapy revisited. Behavior therapy, 35(1), 1-33. https://doi.org/10.1016/S0005-7894(04)80002-9

Nutting, C. M. (2013). Discovery-Based Learning in World Arts: Creativity and Collaboration in the Undergraduate Fine Arts Class. Teaching Innovation Projects, 3(1).

Richards, J. C., \& Rodgers, T. S. (2014). Approaches and methods in language teaching. Cambridge university press.

Saumell, V. (2012). Guided Discovery for Language Instruction: A Framework for Implementation at All Levels. Buenos Aires: Person.

Sweller, J. (1988). Cognitive load during problem solving: Effects on learning. Cognitive science, 12(2), $257-285$. https://doi.org/10.1016/0364-0213(88)90023-7

Thorsett, P. (2002). Discovery learning theory. Retrieved May, 28, 2013. 